\title{
Terapia Ocupacional no contexto hospitalar: um delineamento da profissáo em hospitais gerais e especializados na cidade de Salvador, $\mathrm{BA}^{1}$
}

\author{
Flora Borges $^{\mathrm{a}}$, Tamiris Freitas Leoni ${ }^{\mathrm{a}}$, Isa Coutino ${ }^{\mathrm{b}}$ \\ ${ }^{a}$ Graduadas em Terapia Ocupacional, Escola Bahiana de Medicina e Saúde Pública - EBMSP, \\ Salvador, BA, Brasil \\ ${ }^{\mathrm{b}}$ Graduada em Terapia Ocupacional, Mestra em Medicina e Saúde Humana, Escola Bahiana de Medicina \\ e Saúde Pública - EBMSP, Salvador, BA, Brasil
}

\begin{abstract}
Resumo: Esta pesquisa descreve as áreas de atuação da Terapia Ocupacional no contexto hospitalar nos hospitais gerais e especializados em Salvador, BA. Tem como objetivo conhecer o perfil deste profissional, além de identificar os procedimentos mais realizados. Trata-se de um estudo transversal, descritivo de abordagem quantitativa, ocorrido no período de março a novembro de 2010. A amostra constitui-se de 23 (67,5\%) terapeutas ocupacionais ( 2 homens e 21 mulheres) de um universo de 34 profissionais que atuam em hospitais na capital baiana. Como instrumento de coleta foi utilizado um questionário elaborado previamente para a pesquisa, contendo 19 questões. Estas se concentraram em três categorias: dados de identificação dos terapeutas, áreas de atuação e procedimentos realizados e Terapia Ocupacional e multidisciplinaridade. Os principais resultados demonstram que 95,2\% dos entrevistados eram mulheres e formados pela Escola Bahiana de Medicina e Saúde Pública. As áreas de pediatria, UTI e Unidades de Queimados foram as que mais contemplaram atuação do terapeuta ocupacional. Com relação aos ciclos de vida, nove $(39,1 \%)$ dos terapeutas ocupacionais trabalham com mais de um ciclo. Já os procedimentos mais utilizados foram as avaliações e orientações. Com relação a multidisciplinaridade, mais da metade, 13 (56,5\%), revelam que esta é de extrema importância para sua prática, bem como traz resultados positivos na recuperação dos pacientes. Conclui-se que a prática do terapeuta ocupacional nesse contexto está em processo de expansão. O número de profissionais de terapia ocupacional no contexto hospitalar na Bahia ainda é pequeno comparando-se com outros estados. Há necessidade de uma descrição mais detalhada que abranja todas as possíveis áreas de atuação e os procedimentos que são realizados pelos terapeutas ocupacionais nos hospitais da Bahia.
\end{abstract}

Palavras-chave: Terapia Ocupacional, Serviços Técnicos Hospitalares, Recursos Humanos.

\section{Occupational Therapy in the hospital context: an outline of the profession in general and specialized hospitals in Salvador, Bahia State}

\begin{abstract}
The aim of this research is to describe the acting areas of Occupational Therapy in the hospital context of the General and Specialized Hospitals in Salvador, State of Bahia. The specific objectives are to identify the procedures performed by the occupational therapist and know the profile of this professional in this context.It is a transversal descriptive study of quantitative approach carried out between March and November 2010. The sample consists of 23 occupational therapists ( 2 men and 21 women), $67.5 \%$ of all area professionals working in hospitals in Salvador. A questionnaire with 19 questions previously elaborated for this research was used as data collection instrument. The questions focused on three categories: identification of therapists; acting areas and procedures performed; and Occupational Therapy and multidisciplinary work. Results showed that $95.2 \%$ of the professionals who work in the city's hospitals are women graduated at the State Medicine and Public Health
\end{abstract}

Autor para correspondência: Flora Borges, Escola Bahiana de Medicina e Saúde Pública, Rua Professor Gerson Pinto, 317, apto.702, Costa Azul, CEP 41760-130, Salvador, BA, Brasil, e-mail: flora.borges@ hotmail.com

Recebido em 4/7/2011; Revisão: 12/1/2012; Aceito em 15/5/2012. 
School ("Escola Bahiana de Medicina e Saúde Pública"). Regarding the Life Cycles, nine of the occupational therapists $(39.1 \%)$ work with more than 1 cycle. Evaluations and guidelines were the most used procedures. Concerning multidisciplinary work, more than half (56.5\%) responded that working together with other professionals is very important to their practice, as well as to their patients' recovery. The specific areas where there is predominance of occupational therapists are pediatrics, intensive care and burn units. It was possible to conclude that the practice of O.T. in this context is under expansion. The amount of professionals working in hospitals in the State of Bahia is still very small in comparison to other states. There is need for a more detailed description involving all possible areas of performance and the procedures realized by Occupational Therapy in the hospitals of the State of Bahia.

Keywords: Occupational Therapy, Ancillary Hospital Services, Human Resources.

\section{Introdução}

A Terapia Ocupacional surgiu no contexto hospitalar. No início de sua história, a profissão tinha como objetivo a restauraçáo da capacidade funcional através da técnica de treinamento de hábitos, como relata Bartalotti e De Carlo (2001). O hospital nesse contexto possuía um caráter mais asilar, atendendo a uma clientela com enfermidades crônicas que encontravam na instituiçấo um local de repouso durante o tortuoso processo de adoecimento e morte (MIRSHAWKA, 1994).

Para que esse modelo de hospital pudesse chegar aos moldes da instituição que a sociedade conhece atualmente, o modelo médico-sanitário, muitos aspectos conceituais precisaram ser revistos. Essas modificaçôes culminaram com o que Foucault (1980) aborda em sua obra, afirmando que as mudanças ideológicas na sociedade foram responsáveis por algumas das transformaçôes conceituais que modificaram os hospitais. Para o autor, o ponto culminante dessa mutação, foi quando a instituição passou a ser um espaço de exercício da Medicina, na intenção da cura e da pesquisa, mudança que ocorre no século XIX.

Complementando o caráter dessas mudanças, Scarazatti (2008) apresenta outras perspectivas, dessa vez ligadas à economia e administração. Dentre elas, a concentração de atividades especializadas, formação de redes e associaçôes, uso intensivo de tecnologias e gerenciamento de processos. O que de fato transformou o ambiente, outrora ocupado por paciente de longa estadia, em um local onde se prezava agilidade, rotatividade e lucro. Todas essas mudanças permitiram a edificaçáo da instituição hospitalar atual. Uma instituição destinada ao diagnóstico e tratamentos de doentes, com planejamento e construção moderna, orientação técnica organizada e administrada, com finalidade de prevenir doenças e promover a saúde (ALMEIDA, 1983).

Nesse contexto, a inserçáo de novos profissionais em um local antes habitado apenas por médicos e enfermeiros se tornou uma realidade (MARINHO; CABALHO, 2001). De acordo com Cecílio e Merhy (2003), esse ambiente tornou-se multidisciplinar. O que de fato sugere uma prática em que o empenho de diversos profissionais é necessário para garantir um processo bem-sucedido de saúde.

No que se refere à inserção do terapeuta ocupacional neste contexto, De Carlo e Luzo (2004) sinalizam que para acompanhar as modernas tendências da instituição hospitalar, o profissional precisou repensar sua prática, tornado-a mais concisa e pertinente para o campo de ação em questão. O que antes era uma prática voltada a intervençáo junto ao paciente crônico, no decorrer dos tempos foi direcionada seguindo uma tendência internacional, como relata De Carlo et al. (2006). Essa tendência privilegiava uma reorganização dos cuidados em saúde, favorecendo períodos de internação mais curtos, resultando dessa maneira em atendimentos voltados a pacientes agudos. $\mathrm{O}$ que pode ser justificado pela atual definição da função do terapeuta ocupacional (TO) no contexto hospitalar. O Conselho Federal de Fisioterapia e Terapia Ocupacional (COFFITO) (CONSELHO..., 2007) define a função do terapeuta ocupacional, como um profissional capaz de realizar:

Procedimento de avaliação, intervenção e orientação, realizado com o cliente internado e/ ou familiar e cuidador, em pronto atendimento, enfermaria, berçário, CTI, UTI (neonatal, pediátrica e de adulto), unidade coronariana, isolamento, brinquedoteca hospitalar, unidade materno-infantil, internação domiciliar e unidade de desintoxicaçáo, para intervenção o mais precoce possível, a fim de prevenir deformidades, disfunçóes e agravos físicos e/ou psicoafetivo-sociais, promovendo o desempenho funcional/ocupacional e qualidade de vida durante a hospitalização [...] (CONSELHO..., 2007). 
Contudo, diante das modificaçóes ocorridas, ainda são escassos os registros das práticas exercidas pelos profissisonais de Terapia Ocupacional ao longo dos tempos. Poucas são as publicações ou dados suficientes que possam discutir de forma sistemática o atual papel desse profissional, tanto no que se refere às áreas de atuação quanto aos procedimentos. Para Galheigo e Antunes (2008), se faz necessário maiores discussóes sobre organização e intervenção no ambiente hospitalar, como por exemplo: a necessidade de delimitação das áreas de atuação do terapeuta ocupacional, e aprofundamento em discussóes acerca da relação entre a visão profissional e sua intervenção (GALHEIGO, 2007).

Em um levantamento realizado pelas pesquisadoras citadas acima, entre 1990 a 2007, foi constatado que, dos estudos publicados sobre essa temática, a maioria referia-se a relatos de experiência ou estudo clínico. Metodologias que em linhas gerais não descreviam os procedimentos e as áreas de atuação realizadas no contexto hospitalar, apenas traziam dados de uma realidade muito peculiar, tornando-se difícil a ampliação de discussões sobre a prática desse profissional. Acrescentando-se ainda que o maior número de publicaçôes se restringe à região sudeste. Fato que as autoras justificam pelo grande número de complexos hospitalares nesses locais, bem como de cursos de Terapia Ocupacional. Realidade que não é uniforme no Brasil, principalmente no estado da Bahia.

O objetivo desta pesquisa é descrever as áreas de atuação do terapeuta ocupacional no contexto hospitalar na cidade de Salvador (BA), além de conhecer o perfil e os procedimentos mais realizados por esses profissionais. Buscando o delineamento dessa prática, possibilitando reflexóes a respeito de sua inserção no contexto hospitalar na capital baiana.

\section{Metodologia}

Trata-se de um estudo transversal, descritivo de abordagem quantitativa realizado no período de março a novembro de 2010, envolvendo 23 terapeutas ocupacionais atuantes em hospitais na cidade de Salvador (BA). Segundo o Datasus (BRASIL, 2010), atualmente, na capital soteropolitana, existem 24 hospitais gerais e 12 especializados entre públicos e privados.

De acordo com os dados fornecidos pelo Conselho Regional de Fisioterapia e Terapia Ocupacional (CREFITO-7) (CONSELHO..., 2008), 34 terapeutas ocupacionais estão distribuídos em apenas 12 hospitais (4 são gerais e 8 especializados). Inicialmente, o objetivo era envolver todos os profissionais. No entanto, $23(67,6 \%)$ constituíram a amostra final. Esse fato ocorreu devido à dificuldade de encontrar alguns desses profissionais listados pelo CREFITO, pois estavam de licença, férias ou não atuavam mais na instituição hospitalar descrita no documento fornecido pelo Conselho. Fizeram parte da pesquisa apenas os terapeutas ocupacionais que estavam em pleno exercício laboral. Todos os profissionais assinaram o Termo de Consentimento Livre e Esclarecido. O trabalho foi submetido e aprovado pelo Comitê de Ética da Escola Bahiana de Medicina e Saúde Pública.

O instrumento utilizado foi um questionário elaborado previamente para o estudo, contendo 19 questôes, distribuídas por alternativas de múltipla escolha, organizadas em três categorias: dados de identificação dos terapeutas; áreas de atuação e procedimentos realizados; e Terapia Ocupacional e multidisciplinaridade. As áreas de atuação foram consideradas em duas perspectivas: ciclos de vida (criança e adulto) e especialidades médicas existentes nos hospitais.

Com relação aos procedimentos, foram consideradas as diversas práticas que ocorrem no contexto hospitalar da cidade de Salvador pelos terapeutas ocupacionais. No âmbito da multidisciplinaridade, foi destacada a relação da prática do profissional terapeuta ocupacional com os demais membros do hospital, assim como o resultado da prática interventiva junto aos pacientes.

Os dados foram agrupados, ordenados e transferidos para um banco de dados (Excel) e, então, tabulados. Como trata-se de um estudo descritivo, foi utilizado o método de análise estatística para descrever e permitir a caracterização dos sujeitos. Para as questôes relacionadas as áreas de atuação, procedimentos e multidisciplinaridade, foi registrada a frequência de incidência.

No que se refere às áreas de atuação por especialidades médicas foi feito um reagrupamento considerando os programas e procedimentos pertencentes a determinada área. Fizeram parte desse agrupamento a Pediatria (Programa Mãe Canguru, RN Mãe - Recém-Nascido Mãe, Alojamento Canguru, Estimulação Precoce), UTI (UTI Neonatal, UTI Pediátrica, Semi UTI Pediátrica), Psiquiatria, Pneumologia (DPOC - doença pulmonar obstrutiva crônica), Unidade de Queimados e a Traumatoortopédico (TRM - traumatismo raquimedular e reabilitação de mão). As demais áreas como Pré e Pós-operatório, Obstetrícia e Unidade de Cirurgia Vascular foram agrupadas como Outros por terem citaçôes inexpressivas.

Para compilar os procedimentos foram utilizados os seguintes critérios: avaliação; orientação (orientação 
familiar, orientação de AVD, intervenção da interface em saúde em grupo e individual, educação em saúde, orientação em relação à conservação de energia, aconselhamento do aleitamento materno); tecnologia assistiva (confecção de órtese, prescriçãao de órtese, adaptação, adequação postural); treino de AVD; intervenção psicossocial; intervenção cognitiva; estimulação sensório-motora; grupo (grupo terapêutico, atividade em grupo e grupo educativo); atividade individual; atividades externas (visita domiciliar e atividades externas de lazer); e outros (manejo de lactação, prevenção de deformidades e sala de espera).

O processo de coleta de dados ocorreu mediante contato prévio com os hospitais. Através deste obtiveram-se os contatos dos profissionais elegíveis para o estudo. Os referidos profissionais foram esclarecidos pelas pesquisadoras sobre o objetivo da pesquisa. Para aqueles que pretendiam ter um tempo para responder foi estabelecido um prazo para a entrega. A aplicação dos questionários para os demais teve duração de 7 a 13 minutos.

\section{Resultados}

\subsection{Perfil do profissional}

O perfil profissional dos terapeutas ocupacionais que compóem este estudo é representado na Tabela 1 , por uma população predominantemente feminina, 21 (91,3\%), graduados, em sua maioria pela Escola Bahiana de Medicina e Saúde Pública, 22 (95,7\%). Dezenove $(82,6 \%)$ dos profissionais entrevistados declararam ter especialização. A maioria da população entrevistada, 14 terapeutas ocupacionais $(60,9 \%)$, atuam no contexto hospitalar há menos de 10 anos, com via de ingresso mediante concurso público, 20 (87\%). Os profissionais, em sua maioria $10(56,5 \%)$, atuam em hospitais gerais e $8(17,4 \%)$ trabalham em regime de plantáo.

Com relação aos ciclos de vida, 9 (39,1\%) dos terapeutas ocupacionais trabalham com mais de um ciclo, sendo o ciclo de vida relacionado a criança e adulto o que mais agrega profissionais. Dentro do quadro de trabalhadores que atuam com o ciclo "criança e adulto", têm-se 8 (34,8\%) dos terapeutas ocupacionais atuando especificamente com "criança", e $6(26,1 \%)$ com "adultos". Vale ressaltar que a população adulta inclui também maiores de 60 anos.

\section{2 Áreas de atuação}

Observa-se na Figura 1 uma prevalência no atendimento na área Pediátrica, com 8 profissionais. Seguido da Pediatria encontra-se a Unidade de Queimados e UTI, ambas com 5 terapeutas ocupacionais. $\mathrm{Na}$ área de Psiquiatria, 4 terapeutas

Tabela 1. Perfil de 23 profissionais terapeutas ocupacionais que atuam em hospitais na cidade de Salvador (BA), no ano de 2010.

\begin{tabular}{|c|c|c|c|}
\hline \multicolumn{2}{|c|}{ Variável } & $\mathrm{N}=23$ & $\%$ \\
\hline Gênero & $\begin{array}{l}\text { Masculino } \\
\text { Feminino }\end{array}$ & $\begin{array}{c}2 \\
21\end{array}$ & $\begin{array}{r}8,7 \\
91,3\end{array}$ \\
\hline Local de formação & $\begin{array}{l}\text { Salvador (EBMSP) } \\
\text { Outros }\end{array}$ & $\begin{array}{c}22 \\
1\end{array}$ & $\begin{array}{r}95,7 \\
4,3 \\
\end{array}$ \\
\hline $\begin{array}{l}\text { Pós-graduação } \\
\text { (especialização) }\end{array}$ & $\begin{array}{l}\text { Sim } \\
\text { Não }\end{array}$ & $\begin{array}{c}19 \\
4\end{array}$ & $\begin{array}{l}82,6 \\
17,4\end{array}$ \\
\hline $\begin{array}{l}\text { Tempo de atuação como } \\
\text { terapeuta ocupacional }\end{array}$ & $\begin{array}{l}<10 \text { anos } \\
\geq 10 \text { anos }\end{array}$ & $\begin{array}{c}14 \\
9\end{array}$ & $\begin{array}{l}60,9 \\
39,1 \\
\end{array}$ \\
\hline $\begin{array}{l}\text { Forma de ingresso no } \\
\text { hospital }\end{array}$ & $\begin{array}{l}\text { Concurso } \\
\text { Indicação } \\
\text { Currículo }\end{array}$ & $\begin{array}{c}18 \\
4 \\
1\end{array}$ & $\begin{array}{r}78,3 \\
17,4 \\
4,3 \\
\end{array}$ \\
\hline Carga horária & $\begin{array}{l}4 \text { horas } \\
6 \text { horas } \\
8 \text { horas } \\
12 \text { horas } \\
\text { Não se aplica* }\end{array}$ & $\begin{array}{l}1 \\
2 \\
6 \\
6 \\
8\end{array}$ & $\begin{array}{r}4,3 \\
8,7 \\
26,1 \\
26,1 \\
17,4 \\
\end{array}$ \\
\hline $\begin{array}{l}\text { Tipo de hospital que } \\
\text { trabalha }\end{array}$ & $\begin{array}{l}\text { Geral } \\
\text { Especializado }\end{array}$ & $\begin{array}{l}13 \\
10\end{array}$ & $\begin{array}{l}56,5 \\
43,5 \\
\end{array}$ \\
\hline $\begin{array}{l}\text { Áreas de atuação por } \\
\text { ciclo de vida }\end{array}$ & $\begin{array}{l}\text { Criança } \\
\text { Adulto } \\
\text { Criança e adulto }\end{array}$ & $\begin{array}{l}8 \\
6 \\
9\end{array}$ & $\begin{array}{l}34,8 \\
26,1 \\
39,1\end{array}$ \\
\hline
\end{tabular}

*Alguns profissionais trabalham em regime de plantão, tendo que cobrir horas mensais e não carga horária diária. 
ocupacionais exercem sua função em contexto hospitalar. As áreas de Pneumologia e Traumatoortopédico são as que têm menor número de terapeutas ocupacionais, ambos com apenas 2 profissionais, o primeiro nas instalações do HG e o segundo em HE. Na categoria Outros, estão classificados o Pré e Pós-operatório; Obstetrícia e Unidade de Cirurgia Vascular. Estas obtiveram apenas a indicação de um terapeuta ocupacional.

Observa-se no Quadro 1 uma versatilidade maior em relação às áreas de atuação da clientela adulta, porém, apesar da diversificação de áreas, o ciclo de vida da criança possui um número maior de profissionais atuantes. $\mathrm{Na}$ categoria criança e adulto, algumas áreas conhecidas por serem voltadas apenas para um ciclo de vida, como Obstetrícia e Pediatria, aparecem como áreas onde todos os ciclos de vida recebem intervençóes.

\subsection{Procedimentos realizados}

Com relação aos procedimentos realizados, verificou-se, como pode ser observado na Figura 2, que a maioria dos profissionais, 22 (95,6\%), utiliza avaliação e orientação no contexto hospitalar. A utilização da tecnologia assistiva, com 19 (82,6\%), foi identificada como o segundo procedimento mais realizado pelos entrevistados. Em seguida aparecem o treino de AVD com 18 (78,3\%) e intervenção

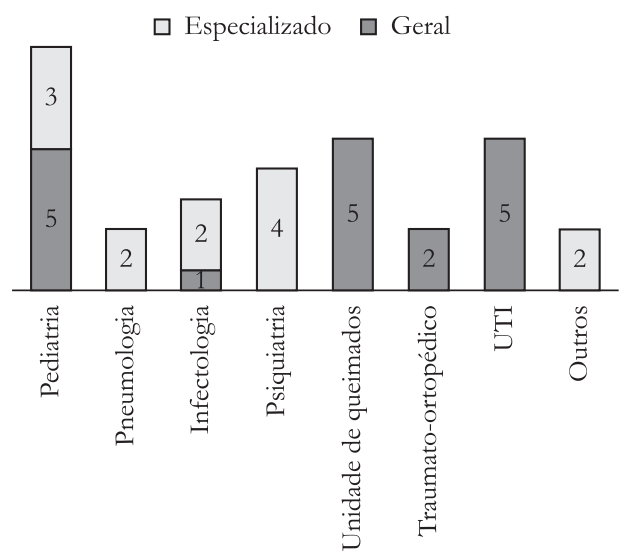

Figura 1. Áreas específicas de atuação no contexto hospitalar. cognitiva, com 15 (65,2\%). Foram citados ainda atividade em grupo; atividade individual e atividades externas, estes últimos procedimentos citados apenas pelos profissionais que atuam na área de Psiquiatria. $\mathrm{Na}$ categoria Outros estão os procedimentos que foram citados apenas por um terapeuta ocupacional, são eles: manejo de lactação, sala de espera e prevenção de deformidades.

\subsection{Terapia Ocupacional e multidisciplinariedade}

Parte dos entrevistados, 13 (56,5\%), revelou que sua prática é compartilhada e valorizada pela equipe do hospital. Essa prática, de acordo com os 23 participantes, traz resultados positivos na recuperação dos pacientes, o que, de acordo com 22 profissionais $(95,6 \%)$, é validada pelos usuários. No questionamento sobre a avaliação pessoal, prevaleceu entre os entrevistados as categorias ótima e boa, ambas com $9(39,1 \%)$ de frequência.

\section{Discussão}

\subsection{Perfil do profissional}

O número de terapeutas ocupacionais atuantes em hospitais na capital baiana ainda se encontra em processo de expansão, diferente das regiōes Sul

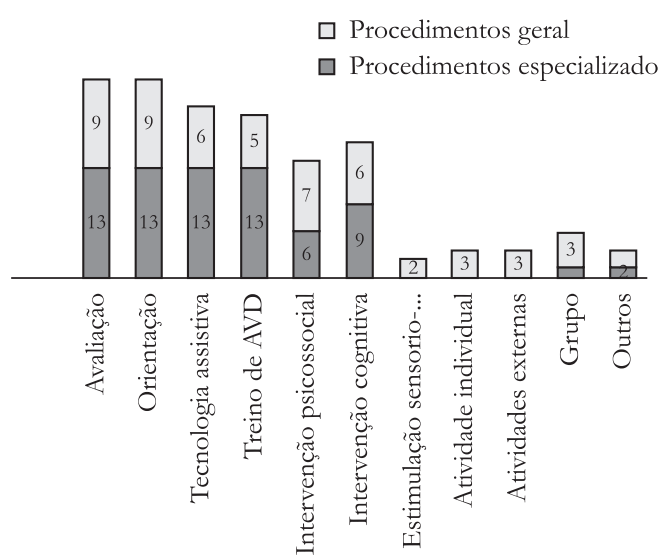

Figura 2. Procedimentos realizados no contexto hospitalar.

Quadro 1. Relação entre ciclos de vida e áreas específicas de atuação por especialidade médica do terapeuta ocupacional em contexto hospitalar.

\begin{tabular}{|l|l|l|}
\hline \multicolumn{1}{|c|}{ Criança } & \multicolumn{1}{|c|}{ Criança e adulto } & \multicolumn{1}{c|}{ Adulto } \\
\hline $\begin{array}{l}\text { Unidade de Queimados; Pediatria } \\
\text { e UTI. }\end{array}$ & $\begin{array}{l}\text { Unidade de Queimados; } \\
\text { Pediatria; Traumato-Ortopédico; } \\
\text { Pneumologia; Obstetrícia e UTI. }\end{array}$ & $\begin{array}{l}\text { Infectologia; Pré e Pós-operatório; } \\
\text { Pneumologia; Unidade de Cirurgia } \\
\text { Vascular; Psiquiatria e UTI. }\end{array}$ \\
\hline
\end{tabular}


e Sudeste, onde concentra-se maior número desses profissionais atuantes nessa esfera (GALHEIGO; ANTUNES, 2008). As autoras sugerem dois aspectos que podem ter relação com essa situação: um desses estaria relacionado ao quantitativo de hospitais que se encontram nessas regiôes onde são em maioria, e o outro pelo número de cursos de Terapia Ocupacional em universidades públicas e de programas de educação continuada (como aprimoramentos e residências profissionais), ou seja, uma realidade totalmente diferente da existente na capital baiana que, além de possuir número de profissionais escassos, o primeiro e único curso de Terapia Ocupacional deixou de ser oferecido em 2009. Atualmente, das 36 instituições hospitalares (BRASIL, 2010) existentes, apenas 12 tem terapeutas ocupacionais. O que significa, do ponto de vista equitativo, menos de um profissional $(0,94)$ para cada hospital.

São poucos os artigos encontrados que tratam da atuaçáo do terapeuta ocupacional em hospital, como o de Galheigo e Antunes (2008) e Galheigo (2007). As publicaçôes, em sua maioria, são relatos de experiências em áreas específicas, como é o caso do artigo de Vasconcelos, Albuquerque e Costa (2006), que descreve a ação do profissional no atendimento de crianças com câncer na unidade de quimioterapia do Hospital Infantil Albert Sabin, em Fortaleza (Ceará). Esse fenômeno pode estar relacionado ao que Galheigo e Antunes (2008) referem com relação à importância do incentivo à pesquisa e publicaçôes. $\mathrm{Na}$ Bahia, até o presente momento, este é o único artigo que aborda o tema.

Os resultados desta pesquisa revelaram que existem terapeutas ocupacionais atuando em mais de um ciclo de vida nos hospitais da capital baiana. Esse episódio pode estar relacionado à escassez de profissionais para atender o grande e variado número de demandas do hospital em relação à intervenção da Terapia Ocupacional para com seus pacientes. Isso pode vir a resultar em profissionais sobrecarregados e impedidos a direcionar sua prática para um único ciclo de vida ou área de atuação, o que permite o desenvolvimento de aptidóes e trabalhos mais direcionados.

Até o momento não há uma demanda definida, nem política efetiva que defina a real atuação do terapeuta ocupacional. A oportunidade de ingresso em hospitais é exclusivamente dependente de concurso público, o que direciona essa população de profissionais para instituiçóes públicas, uma vez que, na capital baiana, esse profissional ainda não faz parte da equipe dos hospitais particulares, e, quando encontrado, está em hospitais psiquiátricos, em regime de hospital-dia. Othero e Costa (2007) demonstram que essa situação não é igual em outras capitais quando citam sua experiência em hospital particular na cidade de São Paulo.

\section{2 Áreas de atuação}

Até a finalização deste artigo, não encontrou-se nenhum material que defina a nomenclatura oficial para a atuação do terapeuta ocupacional em contexto hospitalar. Esse fato tem gerado sucessivas discussōes, por aqueles que se debruçam sobre o tema. Como pôde ser exemplificado pelo documento "Carta de Marilia" (GRUPO..., 2010), produzida pelo Grupo Nacional de Terapia Ocupacional em Contextos Hospitalares, reconhecido pelo COFFITO como veículo oficial para discussão do tema. Essa carta, por sua vez, sinaliza que existem atualmente algumas vertentes para classificar as áreas de atuação do profissional em ambiente hospitalar. Estando elas relacionadas ao contexto específico, nível de complexidade, por programas, clínica médica e ciclos de vida. A mais utilizada é a clínica médica, apesar de ser considerada a menos adequada, pelos profissionais.

A veiculação da classificação por clínica médica, embora amplamente utilizada, sugere algumas discussóes sobre o real papel do terapeuta ocupacional. De Carlo e Luzo (2004) abordam essa questão defendendo que o papel do terapeuta ocupacional deve estar pautado na atividade humana, nas áreas de desempenho, elementos que fazem parte da essência e objeto de estudo e intervenção, independente no contexto de atuação. Para as autoras, o terapeuta ocupacional, nessa conjuntura, tem como meta promover a autonomia e independência do paciente nas atividades que sejam do seu cotidiano e que possam ser realizadas no contexto hospitalar, garantindo, assim, sua qualidade de vida durante o processo de internação.

Ainda com relação às áreas de atuação, outro achado desta pesquisa revela que há um grande número de profissionais atendendo uma clientela infantojuvenil. Fato que não é uma característica apenas dos hospitais baianos. De acordo com Galheigo (2007), há uma prevalência de publicaçôes, em todo o Brasil, relacionadas à atuação do T.O. com esse público. Esse resultado pode estar relacionado ao contexto histórico da profissão. Juntamente com a saúde mental, a atenção à criança e ao adolescente compunham as duas grandes áreas de atuação da terapia ocupacional no início de sua prática. Ainda de acordo com Galheigo (2007), estudos sobre o contexto hospitalar junto ao adulto e ao 
idoso, principalmente em áreas como cardiologia, endocrinologia, gastroenterologia, ainda são escassos. Além disso, em Salvador, não foram encontrados profissionais que trabalhassem nessas áreas.

Uma das hipóteses para a pequena adesão dos terapeutas ocupacionais, nas áreas citadas acima e na pesquisa de Galheigo (2007), pode estar relacionada com a falta de incentivo à pesquisa, já apontado pelas autoras. Por outro lado, é possível considerar que é necessário uma divulgação maior e/ou definição do papel do Terapeuta Ocupacional como promotor de qualidade de vida. E por fim a outra hipótese seria o que Galheigo e Antunes (2008) sinalizam: a baixa quantidade de complexos hospitalares na capital baiana pode ser um fator limitante para ampliação de novas práticas, já que para as autoras a inconstância desse profissional tem relação com o número e a demanda de instituiçôes hospitalares.

\subsection{Procedimentos realizados}

A avaliação, orientação, treino de AVD, tecnologia assistiva (TA) e intervenção cognitiva e psicossocial são procedimentos que se equiparam em frequência tanto em HG quanto em HE. Os demais estáo diretamente relacionados a programas oferecidos pelo hospital ou pela necessidade da clientela, como é o caso de manejo de lactação e estimulação sensório-motora.

A avaliação e orientação são os procedimentos mais citados, dentre os que foram listados, quase $100 \%$ dos profissionais relataram utilizá-los em sua prática. Kudo e Pierri (1997) discutem a importância desses procedimentos quando relatam que estes são primordiais para definição de objetivos de intervenção e agregação da família ao processo de tratamento do paciente.

Não foi possível identificar instrumentos específicos de avaliaçáo utilizados pelos entrevistados. Haja vista que o processo de avaliação em Terapia Ocupacional vem ocorrendo de forma ainda incipiente no Brasil. Muito embora ao longo dos últimos dez anos essa temática tenha avançado bastante, principalmente na tradução e validação de alguns instrumentos. O que ocorre ainda, em linhas gerais, na prática do terapeuta, é a utilização de roteiros de avaliaçáo que contemplam, além de dados da doença, questốes que não estấo diretamente relacionadas ao objeto de intervençáo da profissáo. O que de fato pode está no que descreve Magalhães (1997, p. 23) como uma "[...] incongruência entre o que se avalia e se espera como resultados da profissão [...]".
Assim como as avaliaçóes, que não possuem uma especificidade para o contexto hospitalar, os procedimentos listados, nessa pesquisa, não se diferenciam drasticamente dos procedimentos da Terapia Ocupacional em outros contextos. De Carlo e Luzo (2004) discutem sobre isso quando relatam em seu livro que "o trabalho do terapeuta ocupacional no hospital permeia todo referencial teórico que o profissional segue em qualquer área”. A finalidade da intervenção, nesse campo de ação, é que pode ser diferenciada. Para o COFFITO, o profissional tem o objetivo, dentro do contexto hospitalar, de apenas prevenir agravos e promover saúde, o que para o Ministério da Saúde (BRASIL, 2006) significa "[...] promoção da qualidade de vida e redução de vulnerabilidade e riscos à saúde relacionados aos seus determinantes e condicionantes".

Seguindo essa conceituação, os resultados trazidos por esta pesquisa convergem com o que o Conselho define, pois além de procedimentos, como orientação, atividades externas, TA, entre outros, que têm como finalidade promover e prevenir, também foi citada a "reabilitação de mão". Sabe-se que reabilitação é um dos objetivos do profissional em outros contextos de atuação, mas este não se encaixaria na classificação do COFFITO sobre as competências do terapeuta ocupacional em ambiente hospitalar.

A reabilitação, citada na pesquisa na Bahia, e em artigos como o de Siqueira e Juliboni (2000) - São Paulo -, aponta para questionamentos referentes ao enquadramento dos procedimentos em ambientes hospitalares pelo terapeuta ocupacional. É possível a existência de reabilitação no contexto hospitalar? De Carlo et al. (2006) utilizam o termo "reabilitação de curta duração" em seu artigo. Seria uma alusão ao fato de o profissional realizar alguns procedimentos de reabilitação, mas com o intuito apenas de uma intervençáo pontual, ou existe realmente um processo de reabilitação em ambiente hospitalar?

É notável o conflito no que diz respeito à atuaçáo do T.O. em ambiente hospitalar, quando se comparam literatura e resultados dessa pesquisa com as definiçóes de atuaçáo do terapeuta ocupacional pelo COFFITO, já citadas anteriormente. A nomenclatura "reabilitação", apesar de pouco usada, aparece em artigos e textos da temática hospitalar, mas sempre como coadjuvante de açôes de prevenção e promoção de saúde. De Carlo et al. (2006) dizem que

[...] esta perspectiva de atuação do terapeuta ocupacional, como promotor de qualidade de vida durante e pós-internação, é recente e vem se consolidando progressivamente. 
Talvez, por ser uma prática ainda nova para o terapeuta ocupacional, o profissional não tenha se apropriado completamente. As referências à reabilitação do sujeito são bastante vivas na história da profissão e a caracterizaram por muito tempo. A mudança do trabalho, relacionada ao nível de atenção, pode ser algo muito instável para os profissionais, e a preferência por assegurar-se em uma terminologia mais segura e conhecida em sua prática seja algo inevitável, na atual conjuntura.

Seguindo essa lógica, o profissional vislumbrará aos poucos os novos horizontes conquistados com a ampliação e divulgação de sua prática, e quando for possível perceber que ele pode ser promotor, assim como foi, é e será um reabilitador.

\subsection{Terapia Ocupacional e multidisciplinariedade}

A multidisciplinaridade hospitalar é definida por Tonetto e Gomes (2007) como a ação de vários profissionais que atendem o mesmo paciente de maneira independente. Almeida Filho (1997) acrescenta que na multidisciplinaridade as pessoas trabalham perto, mas não juntas. Os autores Vecina Neto e Malik (2007) relatam que a inserção de profissionais de saúde de diversas áreas de conhecimento tendeu a certo confronto entre esses sujeitos, no que diz respeito a uma disputa na ocupação de posiçôes e definição de intervenções que cabem exclusivamente a cada um dos profissionais. Apesar da crítica dos autores, os resultados dessa pesquisa divergem do pensamento destes. A maioria dos profissionais sente-se satisfeita com a relação entre os colegas de instituição e acredita que sua prática é facilitada por essa dinâmica.

\section{Conclusão}

Até a finalização desta pesquisa, não foram encontrados documentos que definam as áreas de atuação em que o terapeuta ocupacional pode estar inserido em contexto hospitalar. Assim como as áreas, os procedimentos não possuem catalogação. Sabe-se apenas que o profissional tem como objetivo o desempenho funcional/ocupacional do sujeito pensando em prevenção e promoção de saúde. A prática, nessa perspectiva, é fundamentada nas diretrizes que guiam à atuação do profissional em todos os outros contextos, se ajustando às necessidades do ambiente e dos pacientes inseridos no campo de ação hospitalar.
Por se tratar de um trabalho de conclusão de curso, essa pesquisa não pôde ser desenvolvida em um período mais adequado para a sua dimensão. Não alcançou-se o número total de profissionais que atuam no contexto para integrar os resultados finais da investigação, o que traria maior embasamento à pesquisa que seria pautada por dados completos. $\mathrm{O}$ tema e os dados colhidos possibilitavam discussóes importantes, mas que não puderam ser integradas ao corpo do artigo, por fugirem do objetivo traçado para este trabalho. Outro ponto foi a insuficiência de detalhamento dos procedimentos realizados. Os terapeutas ocupacionais não foram solicitados a descrever as etapas existentes em cada procedimento; esses dados poderiam ter gerado conhecimentos acerca dos objetivos e formas de realização de cada procedimento.

O delineamento da profissão em contexto hospitalar informa que em Salvador o número de profissionais nesse campo de ação ainda é pequeno, mas está expandindo. Os procedimentos realizados possuem certa uniformidade e os profissionais estão locados em áreas que atendem em maioria o público infantil. Nesse quadro, a Terapia Ocupacional sofre com a falta de normatização em relação ao seu papel, objetivo e demanda. Mas, em contraponto, grupos de profissionais debatem sobre o assunto a fim de tornar mais específica à prática do terapeuta ocupacional nesse contexto de atuaçáo.

\section{Referências}

ALMEIDA, T. R. R. Perspectivas de sobrevivência do hospital. Revista Paulista de Hospitais, São Paulo, n. 5-6, p. 104-113, maio/jun. 1983.

ALMEIDA FILHO, N. Transdisciplinaridade e saúde coletiva. Ciência \& Saúde Coletiva, Rio de Janeiro, v. 11, n. 1-2, p. 5-20, 1997.

BARTAlOtTi, C. C.; DE CARLO, M. M. R. P. Caminhos da Terapia Ocupacional. In: DE CARLO, M. M. R. P.; BARTALOTTI, C. C. Terapia ocupacional no Brasil: fundamentos e perspectivas. Sáo Paulo: Plexus Editora; 2001. p. 19-38.

BRASIL. Ministério da Saúde. Secretaria de Vigilância em Saúde. Política nacional de promoção da saúde. Brasília: Ministério da Saúde, 2006.

BRASIL. Ministério da Saúde. Departamento de Informática do SUS - DATASUS. Cadastro Nacional dos Estabelecimentos de Saúde do Brasil-CNES. Disponível em: <http://tabnet.datasus.gov.br/cgi/deftohtm.exe?cnes/ cnv/estabba.def $>$. Acesso em: 10 maio 2010.

CECÍLIO, L.; MERHY, E. A integralidade do cuidado como eixo da gestáo hospitalar. In: PINHEIRO, R.; MATTOS, R. A. (Orgs.). Construção da integralidade: cotidiano, saberes e práticas em saúde. Rio de Janeiro: IMS/UERJ/ABRASCO; 2003. p. 197-210. 
CONSELHO FEDERAL DE FISIOTERAPIA E TERAPIA OCUPACIONAL - COFFITO. Lista de Procedimentos da Terapia Ocupacional completa. Brasília: ABRATO. 2007. Disponível em: <http://www.crefito1. org.br/files/procedimentos_descricao.pdf $>$. Acesso em: 06 set. 2010.

CONSELHO REGIONAL DE FISIOTERAPIA E TERAPIA OCUPACIONAL DA $7^{\mathrm{a}}$ REGIÃO - CREFITO-7. Levantamento de terapeutas ocupacionais nos estabelecimentos da SESAB. Salvador: CREFITO-7, 2008.

DE CARLO, M. M. R. P.; LUZO, M. C. M. Terapia Ocupacional: Reabilitação Física e Contextos Hospitalares. São Paulo: Rocca, 2004

DE CARLO, M. M. R. P. et al. Terapia Ocupacional em contextos hospitalares. Prática Hospitalar, São Paulo, v. 3, n. 43, p. 158-164, jan./fev. 2006.

FOUCAULT, M. O Nascimento da Clínica. Rio de janeiro: Forense-Universitária, 1980.

GALHEIGO, S. M. Domínios e temáticas no campo das práticas. Revista de Terapia Ocupacional da Universidade de São Paulo, São Paulo, v. 18, n. 3, p. 113-121, set./dez. 2007.

GALHEIGO, S. M.; ANTUNES, J. R. A caracterização da produção bibliográfica nas práticas hospitalares em terapia ocupacional no Brasil: uma revisão da literatura de 1990 a 2007. Revista de Terapia Ocupacional da Universidade de São Paulo, São Paulo, v. 19, n. 2, p. 91-99, maio/ago. 2008.

GRUPO NACIONAL DE TERAPIA OCUPACIONAL EM CONTEXTOS HOSPITALARES. Carta de Marilia. Marília: Grupo nacional de Terapia Ocupacional em Contextos Hospitalares, 2010.

KUDO, A. M.; PIERRI, S. A. Terapia Ocupacional com crianças hospitalizadas. In: KUDO, A. M. et al. Fisioterapia, fonoaudiologia e terapia ocupacional em pediatria. São Paulo: Sarvier, 1997. p. 232-45.
MAGALHÃES, L. C. Avaliação de Terapia Ocupacional: o que avaliar e como avaliar. In: CONGRESSO BRASILEIRO, 5.; SIMPÓSIO LATINO AMERICANO DE TERAPIA OCUPACIONAL, 6., 1997, Belo Horizonte. Anais... Belo Horizonte: ABRATO, 1997. v. 1, p. 29-36. MARINHO, M.; CABALLO, V. A prática da psicologia hospitalar. In: MARINHO, M. L.; CABALLO, V. (Orgs.). Psicologia Clínica e da Saúde. Granada: UEL, 2001. p. 263-278.

MIRSHAWKA, V. Hospital, Fui bem atendido: A vez do Brasil. São Paulo: Mrkron books, 1994.

OTHERO, M. B.; COSTA, D. G. Propostas desenvolvidas em cuidados paliativos em um hospital amparador - Terapia Ocupacional e Psicologia. Pratica Hospitalar, São Paulo, v. 9, n. 52, p. 157-60, 2007.

SCARAZATTI, J. L. Tendências na atenção hospitalar. São Paulo: Universidade Federal de São Paulo, Secretaria de Saúde do Rio Grande do Sul, Curso de Gestão hospitalar do Mato Grosso do Sul, 2008. Disponível em: <http:// www.saude.ms.gov.br/controle/ShowFile.php?id=19833>. Acesso em: 07 ago. 2010.

SIQUEIRA, F.; JULIBONI, E. O papel da atividade terapêutica na reabilitação do indivíduo queimado em fase aguda. Cadernos de Terapia Ocupacional da UFSCar, São Carlos, v. 8, n. 2, p. 79-91, 2000.

TONETTO, A. M.; GOMES, W. B. A prática do psicólogo hospitalar em equipe multidisciplinar. Estudos de Psicologia, Campinas, v. 1, n. 24, p. 89-98, 2007. http://dx.doi.org/10.1590/S0103-166X2007000100010

VASCONCELOS, R. F.; ALBUQUERQUE, V. B.; COSTA, M. L. G. Reflexôes junto à criança com câncer. Revista Brasileira de Cancerologia, Rio de Janeiro, v. 52, n. 2, p. 129-137, 2006.

VECINA NETO, G.; MALIK, A. Tendências na assistência hospitalar. Ciência e Saúde Coletiva, Rio de Janeiro, v. 12, n. 4, p. 825-839, 2007.

\section{Contribuição dos Autores}

Autoras responsáveis: Flora Borges e Tamiris Leoni. Colaboradora: Isa Coutinho. Todas as autoras participaram da redaçáo e aprovação final do texto.

\section{Notas}

${ }^{1}$ Pesquisa aprovada pelo Comitê de Ética de Pesquisa em Seres Humanos da EBMSP. Trabalho apresentado no III Simpósio de Terapia Ocupacional - Diferentes práticas de terapia ocupacional em contextos hospitalares, 2010, UNESP - Marília -SP; X Mostra Científica e Cultural EBMSP, 2010, e I Seminário Integrado de Fisioterapia e Terapia Ocupacional no Contexto Hospitalar: Tecendo Redes de Ações, 2010. 
